\title{
Quantitative nailfold capillaroscopy findings in a population with connective tissue disease and in normal healthy controls
}

\author{
Y Kabasakal, D M Elvins, E F J Ring, N J McHugh
}

\begin{abstract}
Objective-To describe and quantify the morphological characteristics of nailfold capillaries that distinguish different forms of connective tissue disease from healthy controls.
\end{abstract}

Methods-A CCD video microscope with fibreoptic illumination and PC based image processing was used to visualise nailfold capillaries and to quantify findings in 23 patients with systemic sclerosis (SSc), 22 patients with systemic lupus erythematosus (SLE), 21 patients with undifferentiated connective tissue disease (UCTD), and 38 healthy controls. Results-Capillary density was reduced in SSc $(5 \cdot 2$ (SD $1 \cdot 3)$ capillaries $/ \mathrm{mm})$ compared with other patient groups and controls. The average number of enlarged capillaries/finger was high in all disease groups $(5 \cdot 5-6 \cdot 6)$ compared with controls (2). However, giant capillaries were most frequent in SSc $(43 \%)$ and were not present in controls. Mild and moderate avascular areas were present in all groups $(35 \%-68 \%)$, but severe avascularity was most frequent in SSc (44\%) compared with other patients $(18 \%-19 \%)$ and controls $(0 \%)$. The greatest frequency of extensive haemorrhage was in SSc (35\%). Conclusions-There is a range of abnormal capillary findings in patients with connective tissue disease and healthy controls. However, certain abnormalities such as a reduced number of capillaries, severe avascularity, giant capillaries, and haemorrhage are most commonly associated with SSc. Videomicroscopy with image processing offers many technical advantages that can be exploited in further studies of nailfold capillaries.

(Ann Rheum Dis 1996; 55: 507-512)

Royal Nation

Hospital for

Rheumatic Diseases,

Upper Borough Walls,

Bath, United Kingdom

Y Kabasakal

D M Elvins

E F J Ring

N J McHugh

Correspondence to:

Dr Neil John McHugh,

Royal National Hospital for

Rheumatic Diseases,

Upper Borough Walls,

Bath BA1 1RI

England.

Accepted for publication

17 April 1996
Nailfold capillaroscopy provides information on capillary morphology in vivo, and has been used as a research tool to study the microcirculation in various connective tissue diseases and Raynaud's phenomenon. ${ }^{1-8}$ Nailfold capillaroscopy with videomicroscopy allows the direct visualisation of the skin capillaries with the use of a microscope attached to a camera and a video recorder, which has additional advantages.
Current interpretation of nailfold capillaroscopy is based largely on qualitative and subjective characteristics, which makes accurate assessment difficult. Maricq et al established a qualitative description based on the characteristic patterns of capillary abnormalities seen in SSc. ${ }^{3}{ }^{10}$ More recent attempts have been made at deriving scales of abnormality for certain characteristics. ${ }^{11} 12$ The range of morphological variation in normal subjects may be considerable. Therefore the interpretation of an abnormal result must be made with caution.

The present study represents an attempt to classify and measure the morphological characteristics of nailfold capillaries in a range of diseases of connective tissue and to compare the results with healthy controls using videomicroscopy.

\section{Materials and methods}

Nailfold capillaroscopy was undertaken on 66 patients with connective tissue disease attending our hospital. Table 1 describes the demographic features of the study group. There were 23 patients with systemic sclerosis (SSc), ${ }^{13} 22$ with systemic lupus erythematosus (SLE), ${ }^{14}$ and 21 with undifferentiated connective tissue disease (UCTD) who had features of a connective tissue disease but did not fulfil criteria for SLE or SSc. ${ }^{15}$ Thirty eight healthy controls were selected from members of our hospital and research laboratory who did not report symptoms of a connective tissue disease at the time of examination. The SSc group was further divided into those with anticentromere antibodies $(n=7)$ and those without $(n=16)$. Anticentromere antibodies were measured by indirect immunofluorescence using HEp-2 cells (Biodiagnostic Ltd, Worcs, UK) and FITC-conjugated polyvalent antihuman immunoglobulin.

Table 1 Demographic characteristics of patients and controls

\begin{tabular}{|c|c|c|c|c|}
\hline & Normal & $S S c$ & $S L E$ & $U C T D$ \\
\hline $\begin{array}{l}\text { No of patients } \\
\text { F:M } \\
\text { Mean (SD) age (yr) } \\
\text { (range) } \\
\text { Mean (SD) } \\
\text { duration of } \\
\text { disease (yr) }\end{array}$ & $\begin{array}{l}38 \\
21: 17 \\
39(11) \\
(20-71)\end{array}$ & $\begin{array}{l}23 \\
23: 0 \\
58(12) \\
(38-79) \\
10(7 \cdot 7)\end{array}$ & $\begin{array}{l}22 \\
22: 0 \\
49(12) \\
(25-68) \\
8 \cdot 9(6 \cdot 3)\end{array}$ & $\begin{array}{l}21 \\
17: 4 \\
42(13) \\
(19-81) \\
5 \cdot 5(6 \cdot 7)\end{array}$ \\
\hline $\begin{array}{l}\text { Anticentromere } \\
\text { antibodies (\%) }\end{array}$ & & $30 \cdot 4$ & 0 & $4 \cdot 8$ \\
\hline
\end{tabular}




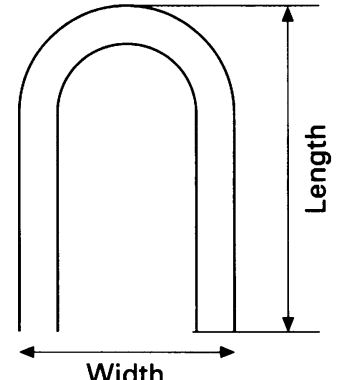

Width

Figure 1 Dimensions of nailfold capillary loop measured in study.
All the capillary examinations were performed on the fourth finger of both hands; the fourth finger usually offers the best capillary visibility. ${ }^{71} 16$ All examinations were performed by the same investigatiors (YK and $\mathrm{DE}$ ), who had no knowledge of the diagnosis. The optical microscope was connected to a video camera with enhanced red sensitivity (WV-CD130/WVL) (60-240-fold magnification). Incident lighting was provided by a Schott fibre-optic illuminator. A U-MATIC video recorder provided the facility to repeatedly scan records and transport the images to a computer (486-IBM clone) for processing and print out. All observations were made after the epithelium was made more transparent by applying immersion or paraffin oil. A $2 \mathrm{~mm}$ graticule was imaged along with each finger to allow quantification of capillary density, size, and length. The video tape recordings were analysed by one investigator (YK) for each finger studied.

The number of all capillaries in the distal row was counted for each finger and the mean

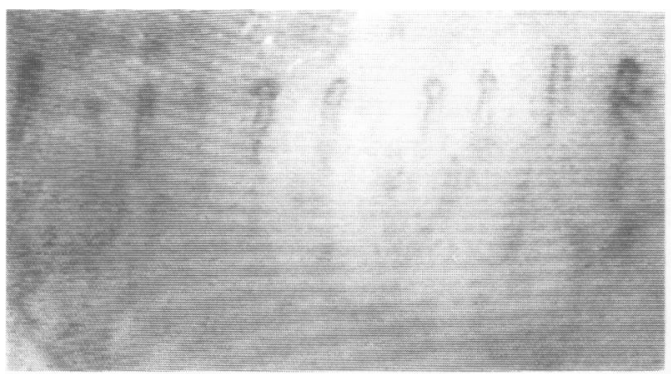

A

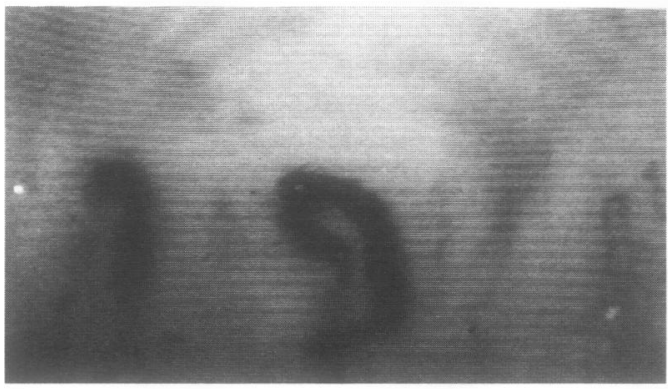
C

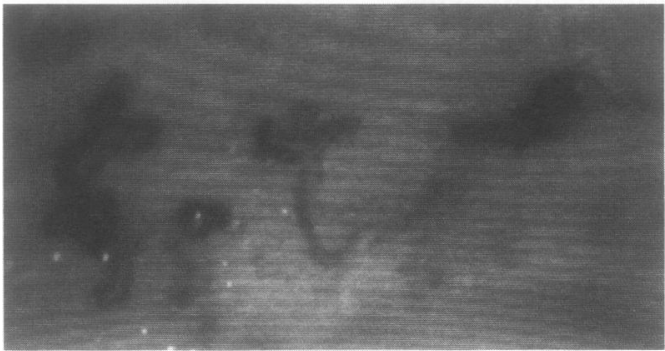

number of capillaries/finger/subject (nailfold capillary density) was derived. The length of the capillary was determined by measuring the projection of the visible part of the capillary in relation to the $2 \mathrm{~mm}$ slide graticule. At least three capillary loops of the fourth finger of both hands were measured as previously described (fig 1). ${ }^{2}$ The mean capillary length of any patient or control was taken as the average length of the three most clearly visible consecutive capillaries. A mean capillary length for a patient or the control group was then derived from the individual means. The mean length of the capillaries in the controls was 215 (SD 40) $\mu \mathrm{m}$. Loops longer than $300 \mu \mathrm{m}$ were classified as elongated capillaries. The frequency of subjects having a mean capillary length greater than $300 \mu \mathrm{m}$ was calculated for each patient group and controls.

Vascular loops were estimated to be of normal width $(<25 \mu \mathrm{m})$ (fig $2 \mathrm{~A}$ ), slightly widened (1-3 $\times$ normal), definitely widened (4-10 $\times$ normal), (fig $2 \mathrm{~B})$, or giant $(>10$ $\times$ normal) (fig $2 \mathrm{C}$ ). The frequency of subjects

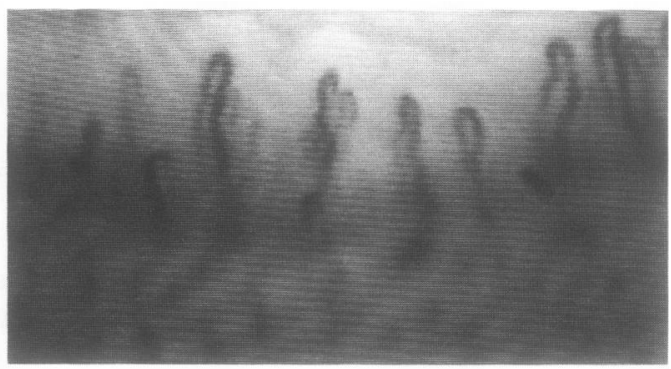

B

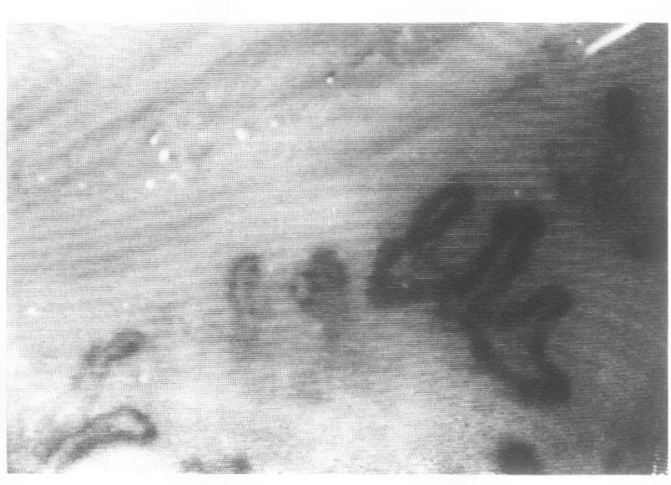

$\mathrm{D}$

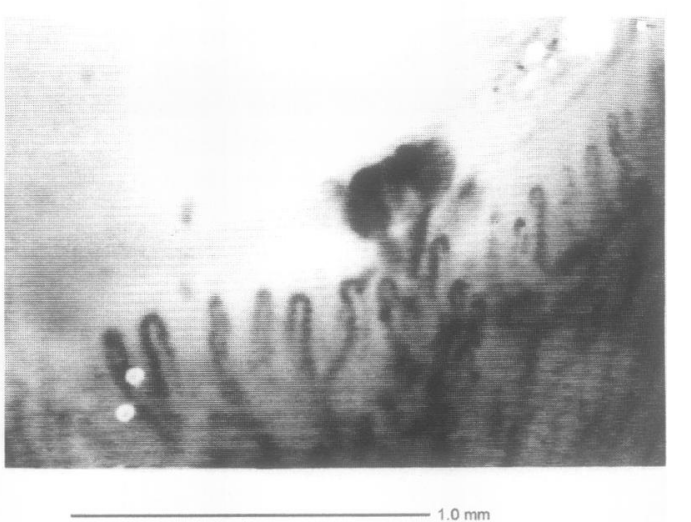

Figure 2 Morphological features of nailfold capillaroscopy: $(A)$ normal recording with open pattern; (B) elongated and widened capillary loops in a normal control; (C) giant capillary loops; (D) bushy capillaries; (E) bizarre capillaries; (F) punctate haemorrhage. 
with more than two definitely widened capillary loops or at least one giant, bushy, or bizarre capillary was calculated for each patient group and for controls.

The most common morphological pattern of the distal row of capillaries was an open pattern (fig 2A), in which the capillary limbs did not cross each other. However, there were certain variations that have been previously described - for example, tortuous (the limbs curled but did not cross), crossed (the limbs crossed at least once), and cuticular (only the end point of the capillary loop was visible). ${ }^{11}$ The dominant morphological pattern was documented for each subject as described. In the absence of a single dominant pattern, the term "mixed pattern" was applied. Uncommon but distinctive morphological alterations were also noted and counted for each finger - for example, bushy (fig 2D) or bizarre capillaries (fig $2 \mathrm{E}$ ).

Avascularity of the capillary bed was classified as grade 0 (nil), grade 1 (mild: one or two discrete areas of vascular deletion), grade 2 (moderate: more than two discrete areas of vascular deletion), or grade 3 (severe: the presence of large, confluent avascular areas). ${ }^{6}$ The frequency of the different degrees of avascularity was calculated for each patient group and controls.

Visibility of the subpapillary venous plexus (PVS) was graded from 0 to 3 ( $0=$ not visible$3=$ prominent over a wide area), adapted from a previous scoring system based on the size of the area in which the subpapillary plexus can be seen. ${ }^{17}$ The subpapillary plexus is the anatomosing network of vessels into which capillary flow continues; these vessels may or may not be visible depending mainly on the size of vessels in the plexus. ${ }^{1}$

Nailfold bleeding/finger was classified as grade 1 (punctate haemorrhages <2/finger), grade 2 (punctate haemorrhages $>2$ ), or grade 3 (confluent areas of haemorrhage). The frequency of grades of haemorrhage was calculated for each patient group and controls.

Statistical analysis was performed by Fisher's exact probability test, and the MannWhitney $U$ test for non-parametric data.

\section{Results}

\section{CAPILLARY DIMENSIONS}

The mean length of capillaries in the control group was 215 (SD 40) $\mu \mathrm{m}$. The upper limit of normal for capillary length was defined as $300 \mu \mathrm{m}$. A small number of control patients $(5 \cdot 2 \%)$ had abnormal mean length capillaries. The frequency of patients with an abnormal mean capillary length was significantly greater in all disease groups (range $44 \%-62 \%$ ) than in controls (fig 3A).

Widened capillary loops were common in disease groups and in controls (table 2). On average there were 2 definitely widened capillary loops/finger in controls. However, the frequency of widened loops/finger was higher in all disease groups than in controls. Whereas only a few controls $(15.8 \%)$ had more than 2 capillary loops/finger that were definitely widened ( $>3 \times$ normal calibre) (fig $2 \mathrm{~B}$ ), the number of patients with more than 2 widened loops/finger was much higher in all disease groups (59\%-65\%) (fig $3 \mathrm{~A})$.
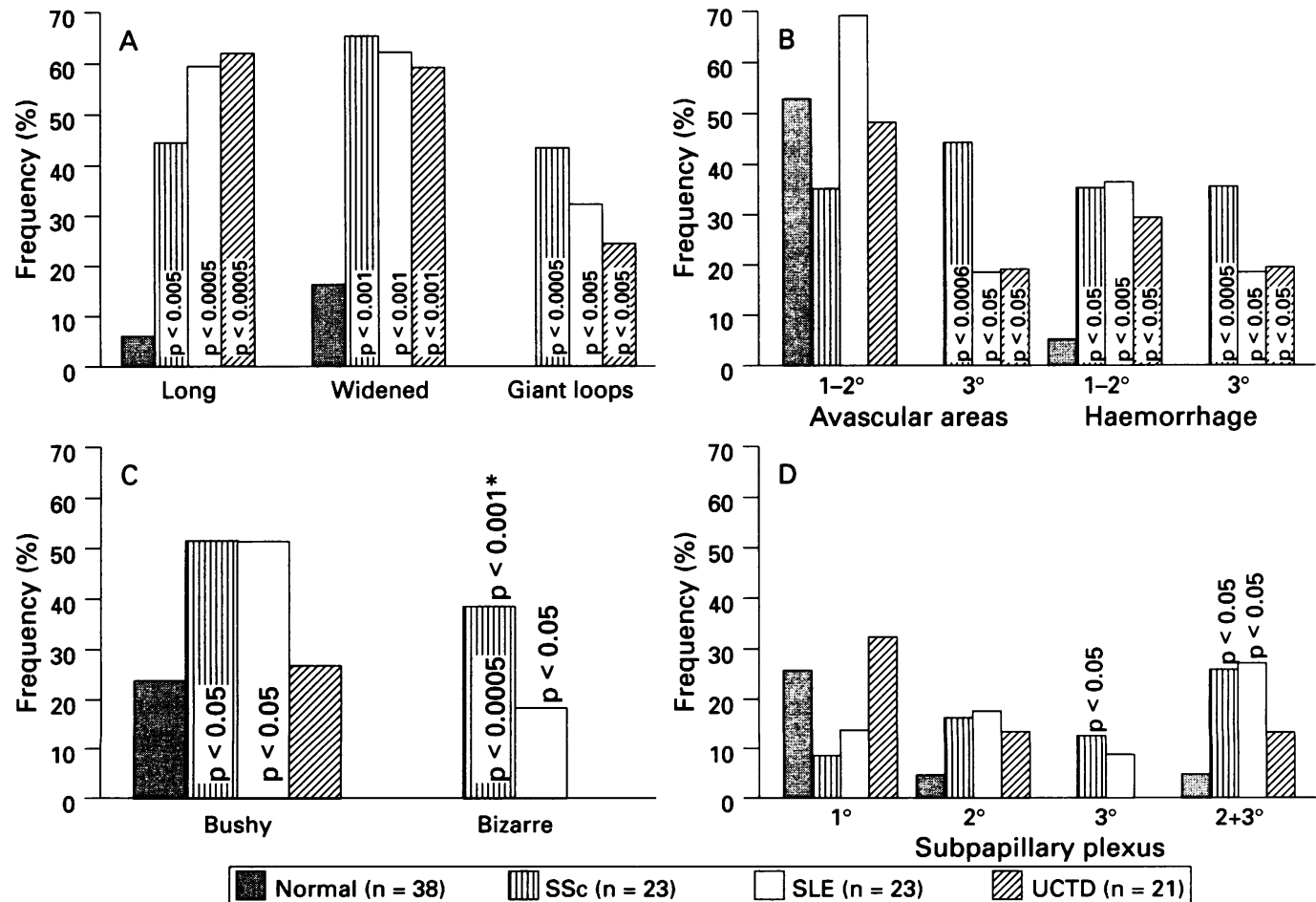

Figure 3 Frequency (\%) of abnormal nailfold capillaroscopy findings in disease groups. Long refers to frequency of members of the group with an abnormal mean capillary length. The frequency of members of the groups with more than two definitely widened capillary loops or at least one giant, bushy or bizarre capillary is given. Levels of significance ( $p$. values) are given compared with controls and ${ }^{\star}$ compared with SLE and UCTD. SSc $=$ Systemic sclerosis; SLE = systemic lupus erythematosus; UCTD = undifferentiated connective tissue disease. 
Table 2 Nailfold capillary dimensions and density in groups with connective tissue disease and in controls

\begin{tabular}{lllll}
\hline & $\begin{array}{l}\text { Controls } \\
(n=38)\end{array}$ & $\begin{array}{l}S S c \\
(n=23)\end{array}$ & $\begin{array}{l}S L E \\
(n=22)\end{array}$ & $\begin{array}{l}\text { UCTD } \\
(n=21)\end{array}$ \\
\hline $\begin{array}{l}\text { Mean No (range) of } \\
\text { definitely widened }\end{array}$ & $2(0-5)$ & $\begin{array}{l}5 \cdot 8(0-23) \\
(\mathrm{p}<0.0005)\end{array}$ & $\begin{array}{l}5 \cdot 5(1-20) \\
(\mathrm{p}<0.005)\end{array}$ & $\begin{array}{l}6.6(0-28) \\
(\mathrm{p}<0.0005)\end{array}$ \\
$\begin{array}{l}\text { capillary loops/finger/person } \\
\text { Mean No (range) of giant }\end{array}$ & 0 & $\begin{array}{l}1.9(0-8) \\
\text { loops/finger/person }\end{array}$ & $\begin{array}{l}1(0-12) \\
(\mathrm{p}<0.0005)\end{array}$ & $\begin{array}{l}0.7(0-6) \\
(\mathrm{p}<0.005)\end{array}$ \\
$\begin{array}{l}\text { Mean }(\mathrm{SD}) \text { capillary density } \\
\text { (capillaries/mm) }\end{array}$ & $7.5(1.3)$ & $\begin{array}{l}5 \cdot 2(1.3) \\
(\mathrm{p}<0.0005)\end{array}$ & $\begin{array}{l}6.8(1.2) \\
(\mathrm{p}<0.005)\end{array}$ & $\begin{array}{l}6.5(1.2) \\
(\mathrm{p}<0.005)\end{array}$ \\
\hline
\end{tabular}

Statistical differences are $v$ controls.

CAPILLARY DENSITY AND AVASCULARITY

The mean capillary density in the control group was 7.5 capillaries $/ \mathrm{mm}$. The nailfold capillary density was significantly reduced in all disease groups compared with controls and was the most reduced in SSc (table 2). Mild to moderate avascularity of the capillary bed was frequent in all groups including controls. However, the control population did not have any extensive areas of avascularity, whereas this feature was most common in SSc (44\%) (fig 3B).

CAPILLARY HAEMORRHAGE

First and second degree haemorrhages were found in a few controls $(5 \cdot 2 \%)$ and more often in all other groups (fig $1 \mathrm{~F}$ and fig $3 \mathrm{~B}$ ). Extensive haemorrhages were especially common in SSc $(35 \%)$ and were not present in normal controls (figure 3B). Haemorrhages were present in $82 \%$ of patients with giant loops.

\section{CAPILLARY PATTERN AND VENOUS PLEXUS}

VISIBILITY

The predominant morphological pattern of the capillaries was similar in all groups including controls, although crossed capillaries were more frequent in SLE and cuticular or mixed patterns were only present in SSc (table 3). Bushy capillaries were present in all disease groups and controls but were most frequent in SLE $(52 \%)$ and SSc (fig 3C). Bizarre capillaries were most frequent in SSc $(40 \%)$ and were not seen in controls (fig 3C). A sclerodermal pattern of nailfold changes has been described by Maricq which consists of the presence of definitely or enormously dilated capillaries, avascular areas, and haemorrhages with the loss of the normal appearance of the capillary bed. ${ }^{10}$ This combination of features was present more often in the SSc group (43\%) than in the normal (0\%: $p<0.0001)$, SLE (9\%: $p<0.01)$, or UCTD $(10 \%$ : $p<0.05)$ groups.

Increased visibility of the subpapillary venous plexus was present to a minor degree

Table 3 Predominant capillary pattern in groups with connective tissue disease and in controls $(\%)$

\begin{tabular}{lllll}
\hline & $\begin{array}{l}\text { Controls } \\
(n=38)\end{array}$ & $\begin{array}{l}S S c \\
(n=23)\end{array}$ & $\begin{array}{l}S L E \\
(n=22)\end{array}$ & $\begin{array}{l}\text { UCTD } \\
(n=21)\end{array}$ \\
\hline Open & 52 & 39 & 46 & 48 \\
Tortuous & 40 & 35 & 32 & 38 \\
Crossed & 8 & 9 & 23 & 14 \\
Cuticular & 0 & 9 & 0 & 0 \\
Mixed & 0 & 9 & 0 & 0 \\
\hline
\end{tabular}

Table 4 Nailfold capillary findings in SSc patients with and without anticentromere antibodies

\begin{tabular}{lll}
\hline & $\begin{array}{l}\text { Anticentromere }+ \\
(n=7)\end{array}$ & $\begin{array}{l}\text { Anticentromere- } \\
(n=16)\end{array}$ \\
\hline $\begin{array}{l}\text { Mean (SD) capillary } \\
\text { density (capillaries/mm) }\end{array}$ & $5 \cdot 1(1 \cdot 3)$ & $5 \cdot 2(1 \cdot 3)$ \\
$\begin{array}{l}\text { Mean No (SD) definitely } \\
\text { widened capillary loops/ } \\
\text { finger/person }\end{array}$ & $6 \cdot 0(4 \cdot 1)$ & $8 \cdot 7(5)$ \\
$\begin{array}{l}\text { Mean No (SD) giant } \\
\text { loops/finger/person }\end{array}$ & $5 \cdot 8(1 \cdot 7)$ & $3 \cdot 8(0 \cdot 9)$ \\
$\begin{array}{l}\text { Bushy capillaries (\%) } \\
\text { Bizarre capillaries (\%) }\end{array}$ & $37 \cdot 5$ & $62 \cdot 5$ \\
$\begin{array}{l}\text { Long capillaries (\%) } \\
\text { Subpapillary plexus (\%): }\end{array}$ & $37 \cdot 5$ & 31 \\
$2^{\circ}$ and 3 & 50 \\
$\begin{array}{l}\text { Avascular areas (\%): } \\
2^{\circ} \text { and 3 }\end{array}$ & 25 & $31 \cdot 5$ \\
$\begin{array}{l}\text { Haemorrhage (\%): } \\
1^{\circ} 2^{\circ}\end{array}$ & 62.5 & $68 \cdot 8$ \\
$3^{\circ}$ & 57 & 25 \\
\hline
\end{tabular}

in all groups. However, in both SSc and SLE the frequency of second and third degree changes in visibility of the subpapillary plexus was significantly greater than in controls (fig 3D).

\section{Anticentromere antibodies}

There were no significant differences within the SSc group separated on the basis of the presence of anticentromere antibodies (table 4). Similarly, there was no significant difference between patients with diffuse $v$ limited skin involvement (data not shown), although a larger number of patients may need to be studied to see signficant differences. Giant loops, bizarre capillaries, and haemorrhage were more common in patients with anticentromere antibodies. Of those patients with giant capillaries, the number of giant capillaries/finger was increased in patients with anticentromere antibodies.

\section{Discussion}

Several abnormal morphological features of nailfold capillaries have been associated with disease. In the current study we used computer processed video images of the nailfold bed to identify features associated with certain connective tissue diseases. We have modified several semiquantitative methods used by others to set a baseline of measurements from which to assess abnormality. Many of our findings are in agreement with those of others-for example, the capillary density in healthy controls was similar to that found in previous studies. ${ }^{11} 1217$ Furthermore, the number of capillary loops/mm was significantly reduced in patients with $\mathrm{SSc}(5 \cdot 2 / \mathrm{mm})$, which is in agreement with values reported by Studer et al $(5 \cdot 49 / \mathrm{mm}){ }^{12}$ The mean nailfold capillary loop length in normal subjects has been reported as ranging from 223.3 (SD 51.9) $\mu \mathrm{m}$ to 234.9 (SD 5.8) $\mu \mathrm{m} .{ }^{2}{ }^{17}$ Our values were only slightly less (215 (SD 40) $\mu \mathrm{m}$ ).

Elongated capillaries were often present in patients with connective tissue disease but did not predict any defined condition. Neither giant capillaries nor bizarre capillaries were found in our normal population. Andreda et al reported bizarre capillaries in $2 \%$ of a normal 
population. ${ }^{11}$ By contrast we found bushy capillaries in a larger number of our controls $(24 \%)$. Bushy capillaries have been associated with mixed connective tissue disease, ${ }^{8}$ yet they were present in almost half of the patients with SSc in our study group, and with the same frequency as in patients with SLE. The highest frequency of definitely widened capillary loops was in the group of patients with SSc.

In SLE characteristic features of nailfold capillaries previously reported include tortuous capillaries, a prominent subpapillary plexus, and an increase in the length of capillaries. ${ }^{13}$ Extremely long capillaries $(>750 \mu \mathrm{m})$ have been reported in up to a third of patients with SLE. ${ }^{8}$ In our SLE population long capillaries and prominence of the subpapillary plexus were more frequent than in the control group, but no more than in the SSc and UCTD groups. Crossed capillaries rather than tortuous capillaries were also more frequent in the SLE group.

In UCTD the presence of capillary abnormalities in patients may confer an increased risk for the eventual development of a defined connective tissue disease. ${ }^{5}$ A greater mean number of dilated capillary loops and an increased avascular score have been found in UCTD compared with primary Raynaud's phenomenon. ${ }^{6}$ In our UCTD population several characteristics, including nailfold capillary length and width, avascular areas, and haemorrhage, were more frequent than in controls. Further follow up of these patients is needed to establish which characteristics are of the most prognostic value.

In SSc the sclerodermal pattern of capillaries characteristic of this condition as described by Maricq $^{10}$ was seen in $43 \%$ of our patients. Similar capillary changes have been found in other conditions ${ }^{8}$ although the sclerodermal pattern was seen in only a few of our patients with SLE or UCTD. Giant or bizarre capillaries, extensive avascular areas, and confluent haemorrhages were the characteristics most distinctive of SSc in the present study. Giant loops were slightly more frequent in patients with ACA, and associated with the highest frequency of haemorrhage, in keeping with the notion that enlarged loops are more prone to extravascation. ${ }^{18}{ }^{19} \mathrm{We}$ did not find any significant differences between subgroups of SSc divided according to the presence of anticentromere antibodies or the extent of skin involvement reported by others. ${ }^{20}{ }^{21}$ However, our subgroups were small and larger numbers may be necessary to detect real differences between serologically defined subsets of SSc.

Video capillaroscopy has advantages over optical photographic techniques. Lighting conditions, focus, and contrast settings on the monitor screen can be optimised for each finger before recording the images on video tape. Lighting angles and camera sensitivity are critical determinants for high quality images. With practice, the entire nailbed area can be recorded in 30 seconds. Therefore, provided the image quality is verified during recording, the examination time with the patient is short. The recorded image can be reviewed at a later date, as often as required, using the pause or freeze frame facility of the tape recorder. An electronic keyboard is used to provide analogue labelling of the recorded images, with the name, date, and finger identification. S-VHS and U-matic recorders are satisfactory, but domestic VHS video camera recorders are not adequate in picture quality. Digitisation of selected frames is possible on a personal computer with a frame grabber board. Commercial software packages are available to optimise the digital image contrast, which can be subsequently printed out with a low cost laser printer on plain paper.

In summary, there seems to be a wide range of normality in nailfold capillaroscopy findings. However, certain features, such as giant or bizarre capillaries, extensive avascularity, and confluent haemorrhage, seem not to be present in a healthy population and should be considered pathological. Reduced number of capillaries, severe avascularity, giant capillaries, and haemorrhages were most commonly associated with SSc. Quantitative assessment of video microscopy images by digital image processing will enhance the value of nailfold capillaroscopy in the future.

We acknowledge the expert technical assistance of Mr Mukesh Mistry.

1 Redish W, Messina E J, Hughes G, McEwen C. Capillaroscopy observations in rheumatic diseases. Ann Rheum Dis 1970; 29: 244-52.

2 Rouen L R, Terry E N, Doft B H. Classification and measurement of surface microvessels in man. Microvasc mes $1972 ; 4: 285-92$.

3 Maricq $H$ R, LeRoy E C. Patterns of finger capillary abnormalities in connective tissue diseases by "widefield" microscopy. Arthritis Rheum 1973; 16: 619-28.

4 Kenik J G, Maricq H R, Bole G G. Blind evaluation of the diagnostic specificity of nailfold microscopy in the connective tissue diseases. Arthritis Rheum 1981; 24: 1159-65.

5 Harper F E, Maricq H R, Turner R E, Lidman R W, LeRoy E C. A prospective study of Raynaud phenomenon and early connective tissue disease. Am $\mathcal{f}$ Med 1982; 72: 883-9.

6 Lee P, Leung F Y-K, Alderdice C, Armstrong S K. Nailfold capillary microscopy in the connective tissue diseases: a capilary microscopy in the connective tissue diseases: a semiquant

7 Lovy M, MacCarter D, Steigerwald J C. Relationship between nailfold capillary abnormalities and organ involvement in systemic sclerosis. Arthritis Rheum 1985; 28: 496-501.

8 Granier F, Vayssairat M, Pascal P, Housset E. Nailfold capillary mixed connective tissue disease. Comparison with systemic sclerosis and systemic lupus erythematosus. Arthritis Rheum 1986; 29: 189-95.

9 Maricq H R, LeRoy E C, D'Angelo W A, et al. Diagnostic potential of in vivo capillary microscopy in scleroderma and related disorders. Arthritis Rheum 1980; 23: 183-9.

10 Maricq H R. Widefield capillary microscopy. Technique and rating scale for abnormalities seen in scleroderma and and rating scale for abnormalities seen in scleroderma and

11 Andreda L E C, Gabriel A Jr, Assad R L, Feraari A J L, Atra E. Panoramic nailfold capillaroscopy: a new reading method and normal range. Semin Arthritis Rheum 1990; 20: $21-31$.

12 Studer A, Hunziker T, Lütolf $O$, Schmidli J, Chen D, Mahler F. Quantitative nailfold capillary microscopy in cutaneous and systemic lupus erythematosus and localized and systemic scleroderma. F Am Acad Dermatol 1991; 24: 941-5.

13 Masi A T, Rodnan G P, Medsger T A Jr, et al. Preliminary criteria for the classification of systemic sclerosis (scleroderma). Arthritis Rheum 1980; 23: 581-90.

14 Tan E M, Cohen A S, Fries J F, et al. The 1982 revised criteria for the classification of systemic lupus erythematosus. Arthritis Rheum 1982; 25: 1271-7.

15 LeRoy E C, Maricq H R, Kahaleh M B. Undifferentiated connective tissue syndromes. Arthritis Rheum 1988; 23: 341-3.

16 Houtman P M, Kallenberg C G M, Wouda A A, The T T. Decreased nailfold capillary density in Raynaud's 
phenomenon: a reflection of immunologically mediated local and systemic vascular disease. Ann Rheum Dis 1985; 44: 603-9.

17 Maricq H R. Technical report "wide-field photography of nailfold capillary bed and a scale of plexus visualisation scores (PVS)". Microvasc Res 1970; 2: 335-40.

18 Grassi W, Core P, Carlino G, Cervini C. Nailfold capillary permeability in psoriatic arthritis. Scand $\mathcal{F}$ Rheumatol 1992; 21: 226-30.
19 Wong M L, Highton J, Palmer D G. Sequential nailfold capillary microscopy in scleroderma and related disorders. Ann Rheum Dis 1988; 47: 53-61.

20 Sato S, Takehara K, Soma Y, Tsuchida T, Ishibashi Y. Diagnostic significance of nailfold bleeding in scleroderma spectrum disorders. $₹ \mathrm{Am}$ Acad Dermatol 1993; 28: 198-203.

21 Sarkozi J, Bookman A A M, Lee P, Keystone E C, Fritzler $M \mathrm{~J}$. Significance of anticentromere antibody in idiopathic Raynaud's syndrome. $A m \mathcal{F}$ Med 1987; 83: 893-8. 